\title{
Simulation of Liberation and Transport of Radium from Uranium Tailings
}

\author{
Maria de Lurdes Dinis ${ }^{1}$, António Fiúza \\ ${ }^{1}$ Department of Mining Engineering, Research Center in Environment and Re- \\ sources - CIGAR. Engineering Faculty of Oporto University. Rua Dr. Roberto \\ Frias, s/n, 4200-465 Oporto, Portugal.mldinis@fe.up.pt;afiuza@fe.up.pt.
}

\begin{abstract}
The uranium tailings contain a large amount of radium, besides other radionuclides like uranium, thorium, polonium and lead. The transport and fate of radionuclides in groundwater are assumed to follow the theoretical approach represented by the basic diffusion/dispersion - advection equation. Our algorithm uses the analytical solution for the one dimensional steady-state transport problem of a reactive substance with simultaneous retardation and radioactive decay. The final output is the radionuclides concentration in a hypothetical well location as function of the elapsed time.
\end{abstract}

\section{Introduction}

The environmental effects resulting from uranium mining activities are mainly derived from the wastes generated by the ore processing.

Uranium mill tailings are the solid residues resulting from the leaching of the ores. The tailings possess, in their composition, hazardous radioactive and toxic by-products and are generally disposed in open air piles. Since only the first four isotopes in the uranium 238 decay series are extracted, all other member of the family remain in the tailings at their original activities. In addition, small residual amounts of uranium are left in the tailings, depending on the efficiency of the extraction process used. Although the activity in most uranium tailings is relatively low, some radiological hazard will last virtually forever because of the long halflife of the radionuclides involved.

The uranium tailings disposal represents the highest potential source of environmental contamination for the great majority of uranium mining activities. Approximately $70 \%$ of the original activity from uranium ore remains in the tailings and it is essentially due to the ${ }^{230} \mathrm{Th}$ and its descendents, in particular ${ }^{226} \mathrm{Ra}$. The radionuclides in the tailings are more mobile and chemically reactive than in 
original ore. They are now potentially more able to enter in the environment by seepage, leaching and as dust, becoming a contamination source to the air, soil, superficial water and groundwater.

Radium is often considered to be the most important radiotoxic decay product in the uranium decay series not only by its high radioactivity but because it also produces radon ${ }^{222} \mathrm{Rn}$ ), an inert gas whose decay products can cause lung cancer. Airborne radon degrades into a series of short half-life decay products that are hazardous if inhaled. However, ${ }^{210} \mathrm{~Pb}$ is also an important decay product, both because of its radiotoxicity and because of the mobility of ${ }^{210} \mathrm{Po}$, a subsequent daughter.

Uranium mill tailings also contain potentially dangerous materials such as arsenic and selenium. These toxic and other radioactive materials like radium and uranium may get into the human body mainly through the food chain if they are not properly disposed off.

The transport of radionuclides from a site may occur by the infiltrated precipitation. As water percolates through the pores, some radionuclides are released from the pile where they are exposed, adsorbed to sediments or dissolved in water. This contaminated water may migrate downward to the subsoil and contaminate the groundwater. Once in the groundwater the radionuclides may become accessible to humans or other forms of life when they reach a hypothetical well. The radionuclides present in the water pumped from a well will represent a potential hazard to the nearby population resulting either from a possible ingestion or from its use for irrigation.

This work proposes a two-direction model for simulating the radionuclides release from a uranium tailings pile and its migration process through the soil to the groundwater. The final result is the radionuclide concentration in the groundwater as function of the elapsed time, at a defined distance from the pile, where is considered to be located the well.

\section{Methods and Results}

\section{The Release Mechanism}

The model is divided into three sub-models describing each one different processes: (i) the release mechanism which accounts for the infiltrating water through the cover and the radionuclides leaching out from the contaminated material, (ii) the transport either in the vertical direction, downwards into the soil through the unsaturated zone until an aquifer is reached, either in the horizontal direction, through the saturated zone to the well, and finally (iii) the radionuclides concentration in the well water after the elapsed time.

The algorithm may incorporate four zones with different properties for the vertical transport: the cover, the contaminated zone, the unsaturated zone and the 
saturated zone. The source is considered homogenous, without taking in account the spatial distribution of the radionuclides activity, and is modelled as an infiltration point where the vertical transport starts.

A simple water balance concept is used to estimate the amount of infiltrating water into the soil which will leach the radionuclides from the contaminated matrix (IAEA 1992). The annual infiltrating water rate can be estimated as a function of the cover failure. It may be necessary to consider both components: the intact portion and the failed portion. For the failed portion, the inflow rate will increase as a consequence of the cover cracking or erosion effects.

The infiltrated water will leach some radionuclides adsorbed in soil being contaminated after the contact with the waste material. A simplified model is adopted in our work considering a single-region flow transport where the water flow is assumed to be uniform through relatively homogeneous layers of soil profile (EPA 1996). The simplified model assumes an idealized steady-state and uniform leaching process to estimate the radionuclides concentration in the infiltrated water based on a chemical exchange process.

The leaching model is characterized by a sorption-desorption process where the radionuclide concentration is estimated as a function of the equilibrium partioning between the solid material and the solution. The degree of sorption between the two phases is described by a distribution or partitioning coefficient, $\mathrm{K}_{\mathrm{d}}$. The following equation is used to estimate the leachate concentration under equilibrium partitioning conditions (EPA 1996; Hung 2000):

$$
\mathrm{C}_{\mathrm{wt}}=\mathrm{I}_{\mathrm{t}} /\left[\mathrm{A}\left(\mathrm{D} \theta+\mathrm{D} \rho \mathrm{K}_{\mathrm{d}}\right)\right]
$$

From the above equation, it is known that leachate concentration, $\mathrm{C}_{\mathrm{wt}}\left(\mathrm{Bq} / \mathrm{m}^{3}\right)$ is determined by (1) its $K_{d}\left(\mathrm{~cm}^{3} / \mathrm{g}\right)$ value, which decides the relative transport speed of the radionuclide to that of water in the pore space; (2) soil properties such as bulk density, $\rho\left(\mathrm{g} / \mathrm{cm}^{3}\right)$, the volumetric water content, $\theta$ (dimensionless); and (3) the extent of contamination, which is described by the contaminated zone thickness, D (m), area, A $\left(\mathrm{m}^{2}\right)$ and the amount of radionuclide activity in the source, $\mathrm{I}_{\mathrm{t}}$ (Bq).

Another important mechanism of release is uncontrolled seepage of contaminated liquids contained in the tailings pile. Seepage may initially occur due to the tailings liquids associated with the solids when placed. However, in a longer term, seepage is provoked by water seeping into the tailings moving the radionuclides as water moves through and out of the tailings (IAEA 1992).

\section{The Radionuclides transport}

\section{The Vertical Transport}

The radionuclides are considered to be mobilized sequentially in two directions: vertically downwards into the soil until it reaches an aquifer and then horizontally through the aquifer to a hypothetical well. 
The flow in the vertical direction is simulated for different degrees of saturation depending on the properties of the geologic strata involved. It is also assumed that there is retardation during the vertical transport. The retardation factor $\left(R_{v}\right)$ is the ratio of the average pore water velocity to the radionuclide transport velocity and is calculated assuming that adsorption-desorption process can be represented by a linear isotherm. Following the simplest mathematical approach derived from the Freudlich isotherm equation, the retardation factor can be estimated with the following formula (EPA 1996; Hung 2000):

$$
\mathrm{R}_{\mathrm{v}}=1+\frac{\rho \mathrm{K}_{\mathrm{d}}}{\varepsilon \mathrm{R}_{\mathrm{s}}}
$$

Concentrations of radionuclides in the well water are time-dependent and are function of two transport times - the breakthrough time (vertical transport time to reach the aquifer) and the rise time (horizontal transport time to reach the well). These parameters are combined to estimate the time necessary to transport vertically the radionuclides to the aquifer and also the water velocity in the vertical direction.

\section{The Horizontal Transport}

Among the great variety of hydrologic models available in the literature describing the contaminants transport in groundwater, most of them fail in considering the process of radionuclide decay and its sorption and in this way these models are not adjusted for the exposure assessment purpose.

Radionuclides transport and fate in groundwater follow the theoretical approach of the transport processes represented by the basic diffusion/dispersion-advection equation. The model uses the analytical solution for the one dimensional steadystate transport problem of a reactive substance with radioactive decay. The general equation describing the mass conservation law applied to a reactive solute can be represented by:

$$
\mathrm{D} \frac{\partial^{2} \mathrm{C}}{\partial \mathrm{x}^{2}}-\mathrm{V} \frac{\partial \mathrm{C}}{\partial \mathrm{x}} \pm \frac{\mathrm{r}}{\theta}=\frac{\partial \mathrm{C}}{\partial \mathrm{t}}
$$

In this equation, $\mathrm{D}$ represents the molecular diffusion coefficient $\left(\mathrm{L}^{2} \cdot \mathrm{T}^{-1}\right), \mathrm{C}$

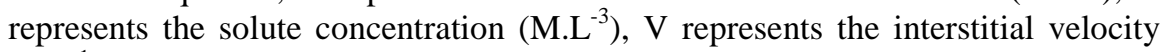
$\left(\mathrm{L} . \mathrm{T}^{-1}\right), \theta$ represents the moisture content (dimensionless) and the $\mathrm{r}$ represents the mass produced or consumed. The term $\pm \mathrm{r} / \theta$ may have different forms depending on the kind of reactions involved. The component dispersive and diffusive is represented by $\partial^{2} \mathrm{C} / \partial \mathrm{x}^{2}$, the advection is represented by $\mathrm{V} . \partial \mathrm{C} / \partial \mathrm{x}$ and the concentration gradient is represented by $\partial \mathrm{C} / \partial \mathrm{x}$.

For the radioactive substances, having a first order kinetic, the parameter $r$, describes the radioactive decay in the mass conservation law:

$$
\mathrm{r}=\frac{\mathrm{d}(\theta \mathrm{C})}{\mathrm{dt}}=-\lambda \theta \mathrm{C}
$$

Radionuclides that finally reach the aquifer will generally be transported at velocities lower or equal than the flow velocity of the aquifer due to retardation by the sorption phenomena. The retardation factor, $\mathrm{R}$, is used to estimate the time that 
it takes to transport the radionuclides to the well located at a defined distance and can be estimated by the equation (2) assuming that all hydro-geologic parameters refers to the aquifer material, namely, the aquifer material density, the aquifer porosity (dimensionless) and the distribution coefficient between the radionuclide and the aquifer material.

The following expression describes the basic equation for the advective and dispersive transport with radioactive decay and retardation for the radionuclide transport in the groundwater:

$$
\mathrm{D} \frac{\partial^{2} \mathrm{C}}{\partial \mathrm{x}^{2}}-\mathrm{V} \frac{\partial \mathrm{C}}{\partial \mathrm{x}}-\mathrm{R} \frac{\partial \mathrm{C}}{\partial \mathrm{t}}-\lambda \mathrm{RC}=0
$$

Using this equation implies that the flow of the fluid carrying the radionuclides is steady, uniform and one-dimensional, that the dissolved radionuclides are in equilibrium with those adsorved by the solids in the aquifer formation and that the radioactive decay occurs for both dissolved and adsorved radionuclides. The analytical solution was obtained assuming the mathematical simplification as presented by Hung (Hung 1986) in his optimum groundwater transport model. The term for the contaminant concentration, $\mathrm{C}$, was replaced by the rate of radionuclide transport, Q, in the previous equation (Hung 1986):

$$
\mathrm{Q}^{\prime}(\mathrm{t})=\mathrm{Q}_{0}\left(\mathrm{t}-\frac{\mathrm{RL}}{\mathrm{V}}\right) \mathrm{e}^{\left[-\left(\lambda_{\mathrm{d}} \mathrm{R} L\right) / \mathrm{V}\right]}
$$

One of the simplifications assumed is neglecting the dispersion term $\left(\partial^{2} \mathrm{Q} / \partial \mathrm{x}^{2}\right)$ and in this way Q'(t) $(\mathrm{Bq} / \mathrm{yr})$ represents the rate of radionuclide transport with the dispersion effects neglected. The others parameters represents the rate of radionuclides transport at $\mathrm{x}=0, \mathrm{Q}_{0}(\mathrm{~Bq} / \mathrm{yr})$, the elapsed time, $\mathrm{t}(\mathrm{yr})$, the retardation factor, $\mathrm{R}$ (dimensionless), the distance from the disposal site to the well point, $\mathrm{L}(\mathrm{m})$, the interstitial groundwater velocity, $\mathrm{V}(\mathrm{m} / \mathrm{yr})$, and the radioactive decay constant, $\boldsymbol{\lambda}_{\mathrm{d}}$ $\left(\mathrm{yr}^{-1}\right)$.

Neglecting the dispersion in the basic transport equation will generate an inherent error that should be compensated. In this way, a correction factor is used to compensate the effects of longitudinal dispersion (Hung 1986).

The correction factor, $\eta$, is defined as a function of the Peclet number and the parameter expressed by $\lambda_{\mathrm{d}}$.R.L/V. This parameter represents the ratio of the radioactive decay constant, $\lambda_{\mathrm{d}}$, and the transport number V/(R.L). The Peclet number is a dimensionless parameter which expresses the diffusion process and the convective transport. The transport number can be estimated by the hydrologic system parameters (Hung 1986)

$$
\eta=\frac{\mathrm{e}^{\left[\left(\mathrm{P}_{\mathrm{e}} / 2\right)-\left(\mathrm{P}_{\mathrm{e}} / 2\right)\left(\sqrt{1+\left(4 \lambda_{\mathrm{d}} \mathrm{RL}\right) /\left(\mathrm{P}_{\mathrm{e}} \mathrm{V}\right)}\right)\right]}}{\mathrm{e}^{\left[-\left(\lambda_{\mathrm{d}} \mathrm{RL}\right) / \mathrm{V}\right]}}
$$

The final analytical solution for the radionuclides transport with the dispersion effects considered, $Q_{p}(t)$ (Hung 1986):

$$
\mathrm{Q}_{\mathrm{p}}(\mathrm{t})=\eta \mathrm{Q}_{0}\left(\mathrm{t}-\frac{\mathrm{RL}}{\mathrm{V}}\right) \mathrm{e}^{\left[-\left(\lambda_{\mathrm{d}} \mathrm{R} L\right) / \mathrm{v}\right]}
$$




\section{The Radionuclides Concentration in the Well Water}

The processes that control the radionuclides fate as they are transported from the source to the receptor may be divided into the radioactive decay and the transport destiny. These last processes (sorption, ion exchange and precipitation) can facilitate or retard the movement of groundwater contaminants but radioactive decay always result in loss of the initial activity of the radionuclide. However, radioactive decay also result in an increase of radioactive or chemically toxic daughter products as the parent radionuclides disintegrates.

The leachate concentrations will be diluted by mixing with the ambient water along the travel path. As a first approximation, the degree of mixing may be estimated by the aquifer volumetric flow rate which means the total rate of flow available for dilution, $\mathrm{W}_{\mathrm{A}}\left(\mathrm{m}^{3} / \mathrm{yr}\right)$.

The concentration of a radionuclide in a downgradient receptor may subsequently be adjusted for dilution using the $\mathrm{Q}_{\mathrm{p}}(\mathrm{t})$ obtained from the previous expression in conjunction with the aquifer volumetric flow rate. As a result, a simple algebraic equation (9) can be used to estimate the radionuclides concentration in the well water, $\mathrm{C}_{\mathrm{wp}}\left(\mathrm{Bq} / \mathrm{m}^{3}\right)$, corrected for dilution, using the radionuclide transport through the section of the well, $\mathrm{Q}_{\mathrm{p}}(\mathrm{Bq} / \mathrm{yr})$ and the rate of contaminated water flow available for dilution, $\mathrm{W}_{\mathrm{A}}\left(\mathrm{m}^{3} / \mathrm{yr}\right)$. This term, $\mathrm{W}_{\mathrm{A}}$, is calculated considering the lateral dispersion of the flow, the depth of the well penetrating into the aquifer, the groundwater velocity, the porosity of the aquifer material, the site width and the distance from the center of the contaminated site to the well. The final output is the radionuclides concentration in a hypothetical well location as function of the elapsed time (Hung 2000).

$$
\mathrm{C}_{\mathrm{wp}}=\frac{\mathrm{Q}_{\mathrm{p}}}{\mathrm{W}_{\mathrm{A}}}
$$

\section{A Case Study}

The model was applied to a specific contaminate site, the Urgeiriça uranium tailings. The Urgeiriça uranium mine is located in the north of Portugal, near Nelas (Viseu). The mine is surrounded by small farms and country houses, with most of the local population living in a village within about $2-\mathrm{km}$ of the mine.

The mine's exploitation began in 1913 for radium extraction. The activity of the Urgeiriça mine was maintained until 1944 then exclusively dedicated to the radium production. In 1951, a chemical treatment unit for the production of lowgrade $\mathrm{U}_{3} \mathrm{O}_{8}$ concentrates was built, and in 1967 was transformed into a modern unit with the capacity to treat about 150 t of ore per day (Bettencourt et al. 1990). In 1991, local mining stopped but the facilities were still being used for the treatment of ores from other mines in the same region until 2000.

The exhausted exploitation and treatment of the uranium ore in the Urgeiriça mine, has led to an accumulation of large amounts of solid wastes (tailings). About $4 \times 10^{9} \mathrm{~kg}$ of rock material was routed into natural depressions confined by 
dams that cover an area of about $0,13 \mathrm{~km}^{2}$. A tailings pile is located near the mine and in addition, liquid effluents after neutralization and decantation were used to be discharged into a small streamlet. The solid wastes are composed mainly of sand and silt particles, transported as a pulp to the site from the counter-current decantation, that were previously submitted to grinding and acid leaching.

The model was tested in different situations varying some of the parameters involved. Some parameters were adopted from published data referring to the Urgeiriça site (Bettencourt et al. 1990; Reis et al. 2000; Pereira et al. 2004). The unknown parameters were estimated from available data.

Data concerning meteorological parameters, namely precipitation and evaporation were used for estimate the infiltrating water rate into the contaminated zone. The precipitation and evaporation data refers to the Nelas meteorological station. It was considered that there is no irrigation in the local so the only inflow rate to the water balance is due to precipitation rate.

The calculating procedure uses the following steps: i) estimative of infiltrating water rate, ii) estimative of the radionuclide concentration in the leachate, iii) the transport in the vertical direction through the unsaturated zone, vi) estimative of the radionuclide release rate to groundwater, v) the transport in the horizontal through the saturated zone and vi) the radionuclide concentration in the well.

The contaminated site is considered to be a total area of approximately 133000 $\mathrm{m}^{2}$. We considered, for this case, the inexistence of a covering system in this area and that surface is homogeneous without cracking. The radionuclide concentration was also considered homogenous and equal in all the contaminated area: an average value for each radionuclide concentration was used.

Local hydro-geological conditions were considered for each zone where the radionuclides transport occurs (Pereira et al. 2004), namely for the contaminated zone, for the unsaturated zone and for the saturated zone, different density, porosity, hydraulic conductivity, radionuclide distribution coefficient and thickness, were used. The well is located at the downgradient edge of the contaminated zone.

We considered as initial conditions that for $\mathrm{t}=0$ the well water is not contaminated and the simulation is done from 0 year until 300 years after the groundwater contamination starts. For the breakthrough time no radionuclides can reach the aquifer until the model simulation exceeds the travel time. As final output we obtain the radionuclide concentration in the well water and also the cumulative rate of radionuclides transported to the well, after the time considered.

The nuclides initially considered were uranium, radium, thorium, polonium and lead. The concentration in the well water was calculated for each radionuclide.

The results presented were obtained for the same case study applied for uranium and radium. Other radionuclides were considered and the results were in accordance with the expected. Due to the slow rates of contamination migration, only radionuclides with relatively long half-life are of importance in the transport process. This is what happened with polonium: a nil concentration was obtained in the well water and it can be explained by the fact that polonium half-life is three minutes for the isotope ${ }^{218} \mathrm{Po}$ and $1,6 \times 10^{-4}$ seconds for the isotope ${ }^{214} \mathrm{Po}$ which means that their half-life is not enough to be mobilized by the groundwater flow and they will decay before they can reach the exposition point, the well water. 
The radionuclides ${ }^{230} \mathrm{Th}$ and ${ }^{210} \mathrm{~Pb}$ are generally not transported to significant distances due to the particle reactive nature of thorium, which will tend to react slowly in-situ with water, oxygen and other compounds; by in-situ decay forms a wide variety of compounds; the lead has a great tendency to be adsorbed by the aquifer sediments (although such transport may occur under acid conditions). Consequently, the radionuclides of primary concern are ${ }^{238} \mathrm{U},{ }^{234} \mathrm{U}$ and ${ }^{226} \mathrm{Ra}$. The figures bellow shows the results obtained for radium and total uranium (combined ${ }^{234} \mathrm{U}$ and $\left.{ }^{238} \mathrm{U}\right)$.

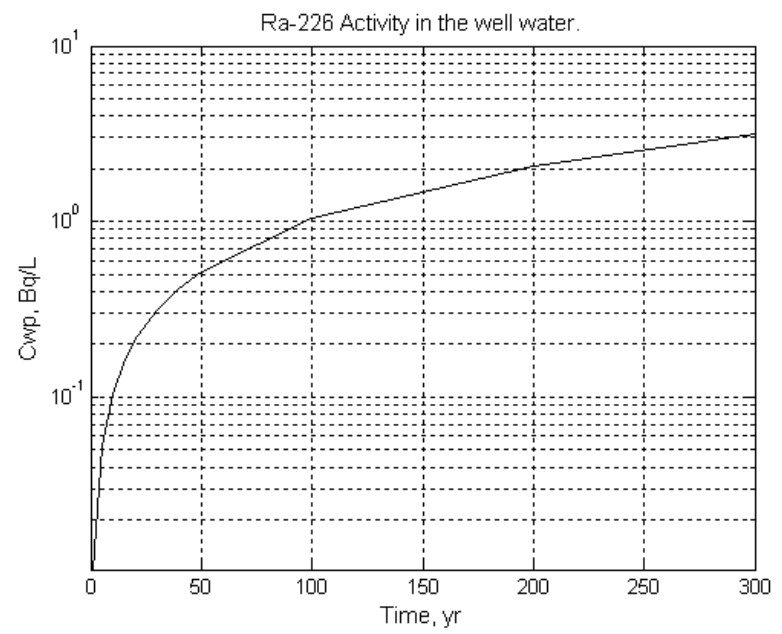

Fig. 1. Radium activity concentration in the well water, Bq/L.

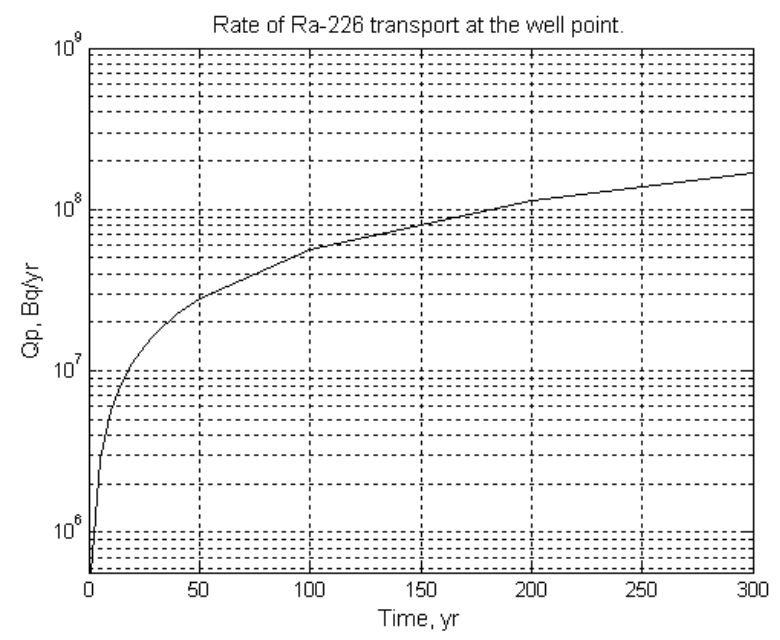

Fig. 2. Cumulative rate of radium release, $\mathrm{Bq} / \mathrm{yr}$. 


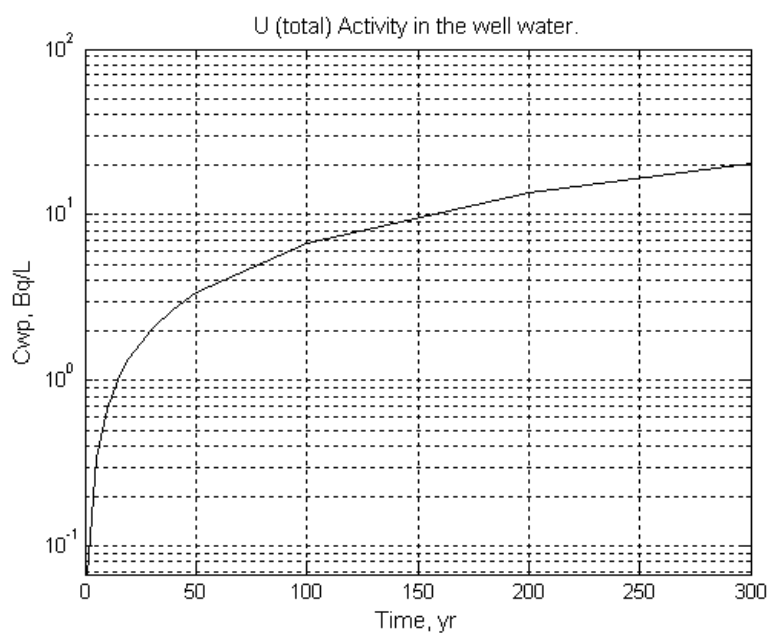

Fig. 3. Uranium activity concentration in the well water, $\mathrm{Bq} / \mathrm{L}$.

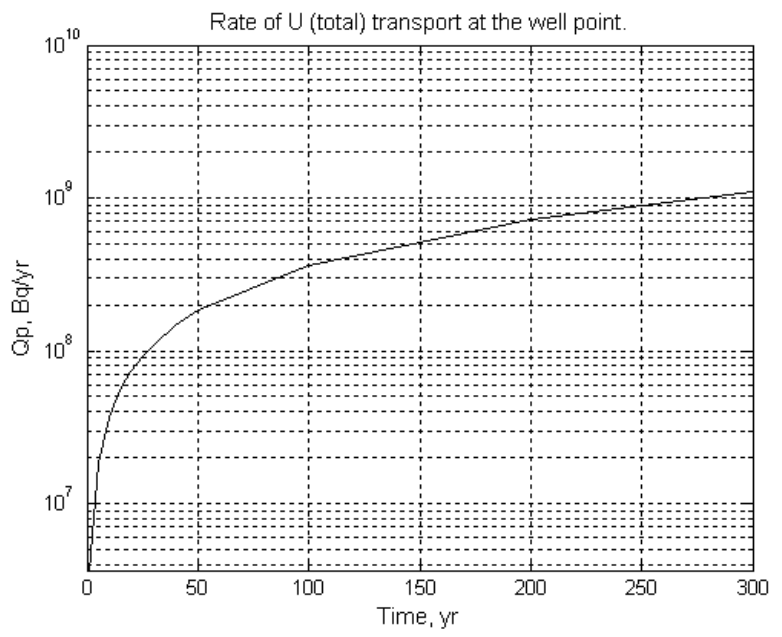

Fig. 4. Cumulative rate of uranium release, $\mathrm{Bq} / \mathrm{yr}$.

\section{Conclusions}

The work presented may be considered a first approach in modeling the radionuclide release and transport in the groundwater to the purpose of exposure assessment to contaminated water from wells located close to a uranium tailings pile. It 
predicts the cumulative amount of radionuclides flowing through a section and also the amount of radionuclides reaching the well point.

We should be aware that the application of an analytical solution is limited by its specific form of boundary conditions which can result from some approximation even before the analytical solution can be applied. This will generate some error due to the approximation of the boundary conditions. However, the magnitude of this error depends largely on the conformity between the local conditions and those of the theoretical model.

The model is idealized for a situation in which the hydrological strata can reasonably be approximated by a sequence of uniform, horizontal data.

Many soil specific parameters can affect the amount of time that it takes for a radionuclide to travel to groundwater. We should refer the difficulties that may be found when trying to obtain the data needed to characterize the soil specific parameters for the contaminated soil, the unsaturated zone and the saturated zone for a particular contaminated site. Also the water transporting the radionuclides depends on detailed variations of the hydraulic properties of the media through which the water passes and even during the site characterization phase these data are rarely available. The accuracy of the results predicted is determined by the accuracy of the effective input parameters used.

\section{References}

Bettencourt A. O., Teixeira M. M., Elias M. D., Madruga M. J. (1990), Environmental Monitoring in Uranium Areas. In: Environmental Behaviour of Radium, Vol. 2. Technical Reports Series N. ${ }^{\circ} 310$, pp. 281-294, IAEA, Vienna.

EPA (1996), Documenting Ground-Water Modeling at Sites with Radioactive Substances. U.S. Environmental Protection Agency, 9355.0-60, EPA 402-R-96-003, PB96-963302, Washington, D.C.

Hung C. Y. (1986), An Optimum Groundwater Transport Model for Application to the Assessment of Health Effects Due to Land Disposal of Radioactive Wastes. Proceedings of Nuclear and Chemical Wastes Management, Vol. 6, pp. 41-50.

Hung C. Y. (2000), User's Guide for PRESTO-EPA-CPG/POP Operation System. U.S. Environmental Protection Agency, Version 4.2, EPA 402-R-00-007, Washington, D.C.

IAEA (1992), Current Practices for the Management and Confinement of Uranium Mill

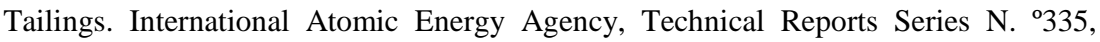
IAEA, Vienna.

Pereira A.J.S.C., Dias J.M.M., Neves L.J.P.F. \& Nero J.M.G. (2004), Modelling Efficiency of a Rehabilitation Plan for a Uranium Mill Tailing Deposit (Urgeiriça, Central Portugal). XI International Congress of the Radiation Protection Association, Madrid, Spain, 23-28 May.

Reis M., Faísca C., Brogueira A., Teixeira M. (2000), Avaliação da Exalação de ${ }^{222}$ Rn para a Atmosfera em Barragens de Estéreis das Minas da Urgeiriça. Report DPRSN Serie A, N. ${ }^{\circ}$, Sacavém, Portugal. 